\title{
Expectations, Deflation Traps and Macroeconomic Policy*
}

\section{George W. Evans, University of Oregon, University of St. Andrews Seppo Honkapohja, Bank of Finland}

July 6, 2009; revised

\begin{abstract}
We examine global economic dynamics under infinite-horizon learning in a New Keynesian model in which the interest-rate rule is subject to the zero lower bound. As in Evans, Guse and Honkapohja (2008), we find that under normal monetary and fiscal policy the intended steady state is locally but not globally stable. Unstable deflationary paths can arise after large pessimistic shocks to expectations. For large expectation shocks pushing interest rates to the zero lower bound, temporary increases in government spending can be used to insulate the economy from deflation traps.
\end{abstract}

JEL Classification: E63, E52, E58.

Keywords: Adaptive Learning, Monetary Policy, Fiscal Policy, Zero Interest Rate Lower Bound

\section{Introduction}

Following the introduction of inflation targeting and related monetary strategies, target inflation rates seem to have fallen to relatively low levels, about

*Early versions of this paper were presented at the Norges Bank conference "Inflation Targeting Twenty Years On," the Conference in honor of Roger Guesnerie, at PSE in Paris, and at the San Francisco Federal Reserve Bank. We are particularly indebted for comments received from Jess Benhabib, David Cobham, Krisztina Molnar, John Williams, and Mike Woodford. 
two to three percent in many countries. This implies that large adverse shocks might push the economy into periods of deflation. This was clearly a major concern in the US during the 2001 recession. The experiences of 2008 and 2009, as well as the earlier experience of Japan since the 1990s, have underscored these concerns and created a situation in which the monetary policy response is constrained by the zero lower bound on nominal interest rates, a phenomenon sometimes called a "liquidity trap." Furthermore, in a liquidity trap there is the potential for the economy to get stuck in a deflationary situation with declining or persistently low levels of output.

The theoretical plausibility of the economy becoming trapped in a deflationary state, and the macroeconomic policies that might be able to avoid or extricate the economy from a liquidity trap, have been examined predominantly from the rational expectations (RE) perspective. One central feature of this literature emphasizes the role of commitment. For example, Krugman (1998) and Eggertsson and Woodford (2003) argue that if the economy encounters a liquidity trap, monetary policy should commit to being expansionary for a considerable period of time, by keeping interest rates near zero even after the economy has emerged from deflation. Another issue concerns the possibility of permanent deflation. Under RE this hinges on the precise form of fiscal policy in the deflationary steady state and on whether this is consistent with the household's transversality condition. See Benhabib, Schmitt-Grohe, and Uribe (2001), Benhabib, Schmitt-Grohe, and Uribe (2002) and Eggertsson and Woodford (2003). A further issue is the impact of the interest rate zero lower bound on the performance of policies during the transition back to the inflation target. ${ }^{1}$

In our opinion, the RE assumption is questionable in an episode of deflation, which is far away from the inflation target and the normal state of the economy, and presents a new environment for economic agents. Our own view, reflected in Evans and Honkapohja (2005) and Evans, Guse, and Honkapohja (2008), is that the evolution of expectations plays a key role in the dynamics of the economy and that the tools from learning theory are needed for a realistic analysis of these issues. As we will see, there is the possibility of a self-reinforcing feedback loop, in which sufficiently pessimistic expectations result in low output and deflation, leading to high real interest rates because of the zero lower bound, which in results in a downward re-

\footnotetext{
${ }^{1}$ See Adam and Billi (2007) and Coenen, Orphanides, and Wieland (2004) for representative recent analyses and further references.
} 
vision of expectations, strengthening the downward pressure on output and deflation.

More specifically, under learning private agents are assumed to form expectations using an adaptive forecasting rule, which they update over time in accordance with standard statistical procedures. The analysis of Evans, Guse, and Honkapohja (2008) was conducted in a standard New Keynesian model with sticky prices using the assumption that the decisions of private agents are based on short-horizon rules. These rules are based on the agents' Euler equations, specifying the optimal trade-off between current and anticipated next period decisions. These anticipations in turn are formed using subjective expectations based on forecasting models that are updated over time using recursive estimation procedures. This framework, often called "Euler-equation learning," yielded important results about formulating robust policies to combat deflationary outcomes. However, its short decision horizon means that one cannot study the implications for current behavior of explicit commitment to future policies. In particular, this learning framework cannot be used to assess the conventional wisdom of the RE literature that an appropriate policy to combat a deflation episode is a commitment to low interest rates for a sustained period in the future.

In this paper we replace Euler-equation learning with the assumption that agents have infinite-horizon decision rules derived from intertemporal optimization under given paths of expectations of aggregate economic variables. This type of formulation is often called "infinite-horizon learning" and it has recently been emphasized by Preston (2005) and Preston (2006). ${ }^{2}$ In general, in this setting the individual consumers need to forecast future interest rates, inflation, income and taxes over the infinite future. As a benchmark, we also assume in this paper that the consumers are fully Ricardian and incorporate the government's intertemporal budget constraint into their own lifetime budget constraint. This last assumption means that the consumption function depends on expected future real interest rates and incomes net of government spending. In this formulation the mix of government financing does not influence private consumption behavior.

The possibility of deflation traps under a standard forward-looking global Taylor rule, emerges as a serious concern. Although the targeted steady state

\footnotetext{
${ }^{2}$ The formulation has earlier been used in Marcet and Sargent (1989) and Evans, Honkapohja, and Romer (1998). Other recent papers include Evans, Honkapohja, and Mitra (2009) and Eusepi and Preston (2007).
} 
is locally stable under learning, a large pessimistic shock to expectations can result, under learning, in a self-reinforcing deflationary process accompanied by declining output. Our results under learning are in stark contrast to what is possible under RE. Benhabib, Schmitt-Grohe, and Uribe (2001) showed that under perfect foresight, in addition to the targeted steady state, there are nonlinear paths that converge to an unintended low-inflation steady state. ${ }^{3}$ Thus the learning dynamics under standard monetary and fiscal policy are even more disturbing than those under RE.

We next consider monetary and fiscal policies that have been suggested to combat the possibility of deflation. One case is aggressive monetary easing in which the Taylor rule is overridden by dropping the interest rate to (very near) zero whenever expected inflation falls below a specified threshold. In our infinite-horizon set-up agents are assumed to understand that this aggressive policy will be in place throughout the future. Strikingly, this policy, although it does offer some protection, is not sufficient to eliminate the possibility of deflation traps if the negative expectations shock is very large. In fact, even if the monetary authorities commit to zero interest rates forever, regardless of the state of the economy, the possibility of a deflation trap remains (although the likelihood is reduced).

These results raise the question of whether there exists a policy that ensures that the economy will never get trapped into a deflationary process and will converge to the targeted steady state. We focus on the policy recommended in Evans, Guse, and Honkapohja (2008). Under this policy aggressive monetary easing is augmented by aggressive fiscal easing when required to keep inflation at or above the threshold. This policy always eliminates the possibility of deflationary spirals and ensures global stability of the targeted steady state.

\section{The Model}

We start with the same economic framework as in Evans, Guse, and Honkapohja (2008). There is a continuum of household-firms, which produce a differentiated consumption good under monopolistic competition and priceadjustment costs. There is also a government which uses both monetary and fiscal policy and can issue public debt as described below.

\footnotetext{
${ }^{3}$ The low steady state can either be one of low positive inflation or deflation, depending on the details of the interest rate rule.
} 
The objective for agent $s$ is to maximize expected, discounted utility subject to a standard flow budget constraint:

$$
\begin{gathered}
\operatorname{Max} E_{0} \sum_{t=0}^{\infty} \beta^{t} U_{t, s}\left(c_{t, s}, \frac{M_{t-1, s}}{P_{t}}, h_{t, s}, \frac{P_{t, s}}{P_{t-1, s}}-1\right) \\
\text { st. } c_{t, s}+m_{t, s}+b_{t, s}+\Upsilon_{t, s}=m_{t-1, s} \pi_{t}^{-1}+R_{t-1} \pi_{t}^{-1} b_{t-1, s}+\frac{P_{t, s}}{P_{t}} y_{t, s},
\end{gathered}
$$

where $c_{t, s}$ is the Dixit-Stiglitz consumption aggregator, $M_{t, s}$ and $m_{t, s}$ denote nominal and real money balances, $h_{t, s}$ is the labor input into production, $b_{t, s}$ denotes the real quantity of risk-free one-period nominal bonds held by the agent at the end of period $t, \Upsilon_{t, s}$ is the lump-sum tax collected by the government, $R_{t-1}$ is the nominal interest rate factor between periods $t-1$ and $t, P_{t, s}$ is the price of consumption good $s, y_{t, s}$ is output of good $s, P_{t}$ is the aggregate price level and the inflation rate is $\pi_{t}=P_{t} / P_{t-1}$. The subjective discount factor is denoted by $\beta$. The utility function has the parametric form

$$
U_{t, s}=\frac{c_{t, s}^{1-\sigma_{1}}}{1-\sigma_{1}}+\frac{\chi}{1-\sigma_{2}}\left(\frac{M_{t-1, s}}{P_{t}}\right)^{1-\sigma_{2}}-\frac{h_{t, s}^{1+\varepsilon}}{1+\varepsilon}-\frac{\gamma}{2}\left(\frac{P_{t, s}}{P_{t-1, s}}-1\right)^{2},
$$

where $\sigma_{1}, \sigma_{2}, \varepsilon, \gamma>0$. The final term parameterizes the cost of adjusting prices in the spirit of Rotemberg (1982). ${ }^{4}$ The household decision problem is also subject to the usual "no Ponzi game" condition.

Production function for good $s$ is given by

$$
y_{t, s}=h_{t, s}^{\alpha}
$$

where $0<\alpha<1$. Output is differentiated and firms operate under monopolistic competition. Each firm faces a downward-sloping demand curve given by

$$
P_{t, s}=\left(\frac{y_{t, s}}{Y_{t}}\right)^{-1 / \nu} P_{t}
$$

Here $P_{t, s}$ is the profit maximizing price set by firm $s$ consistent with its production $y_{t, s}$. The parameter $\nu$ is the elasticity of substitution between two goods and is assumed to be greater than one. $Y_{t}$ is aggregate output, which is exogenous to the firm.

\footnotetext{
${ }^{4}$ We use the Rotemberg formulation in preference to the Calvo model of price stickiness because it enables us to study global dynamics in the nonlinear system. The linearizations at the targeted steady state are identical for the two approaches.
} 
The government's flow budget constraint is

$$
b_{t}+m_{t}+\Upsilon_{t}=g_{t}+m_{t-1} \pi_{t}^{-1}+R_{t-1} \pi_{t}^{-1} b_{t-1},
$$

where $g_{t}$ denotes government consumption of the aggregate good, $b_{t}$ is the real quantity of government debt, and $\Upsilon_{t}$ is the real lump-sum tax collected. We assume that fiscal policy follows a linear tax rule for lump-sum taxes as in Leeper (1991)

$$
\Upsilon_{t}=\kappa_{0}+\kappa b_{t-1}+\eta_{t}
$$

where $\eta_{t}$ is a white noise shock and where $\beta^{-1}-1<\kappa<1$. The restriction on $\kappa$ means that fiscal policy is "passive" in the terminology of Leeper (1991), and implies that an increase in real government debt leads to an increase in taxes sufficient to cover the increased interest and at least some fraction of the increased principal. In a companion paper we plan to investigate the implications of "active" fiscal policy in which $0 \leq \kappa<\beta^{-1}-1$.

We assume that $g_{t}$ is stochastic

$$
g_{t}=\bar{g}+u_{t}
$$

where $u_{t}$ is an observable stationary $\operatorname{AR}(1)$ mean zero shock. From market clearing we have

$$
c_{t}+g_{t}=y_{t}
$$

Monetary policy is assumed to follow a global interest rate rule

$$
R_{t}-1=\theta_{t} f\left(\pi_{t+1}^{e}\right)
$$

The function $f(\pi)$ is taken to be positive and non-decreasing, while $\theta_{t}$ is an exogenous, observable stationary $\mathrm{AR}(1)$ positive random shock with mean 1 representing random shifts in the behavior of the monetary policy-maker. The rule (8) is a nonlinear forward-looking Taylor rule, in which dependence on output expectations is suppressed for simplicity. ${ }^{5}$ We assume the existence of $\pi^{*}, R^{*}$ such that $R^{*}=\beta^{-1} \pi^{*}$ and $f\left(\pi^{*}\right)=R^{*}-1 . \pi^{*}$ can be viewed as the inflation target of the Central Bank, and we will assume that $\pi^{*} \geq 1$. In the numerical analysis we will use the functional form

$$
f(\pi)=\left(R^{*}-1\right)\left(\frac{\pi}{\pi^{*}}\right)^{A R^{*} /\left(R^{*}-1\right)},
$$

\footnotetext{
${ }^{5}$ The main results below would also hold in the case of a contemporaneous-data Taylor rule, which is used in Evans, Guse, and Honkapohja (2008).
} 
which implies the existence of a nonstochastic steady state at $\pi^{*}$. Note that $f^{\prime}\left(\pi^{*}\right)=A R^{*}$, which we assume is bigger than $\beta^{-1}$. Equations (4), (5) and (8) constitute "normal policy".

\subsection{Optimal decisions for private sector}

As in Evans, Guse, and Honkapohja (2008), the first-order conditions for an optimum yield

$$
\begin{gathered}
0=-h_{t, s}^{\varepsilon}+\frac{\alpha \gamma}{\nu}\left(\pi_{t, s}-1\right) \pi_{t, s} \frac{1}{h_{t, s}} \\
+\alpha\left(1-\frac{1}{\nu}\right) Y_{t}^{1 / \nu} \frac{y_{t, s}^{(1-1 / \nu)}}{h_{t, s}} c_{t, s}^{-\sigma_{1}}-\frac{\alpha \gamma \beta}{\nu} \frac{1}{h_{t, s}} E_{t, s}\left(\pi_{t+1, s}-1\right) \pi_{t+1, s} . \\
c_{t, s}^{-\sigma_{1}}=\beta R_{t} E_{t, s}\left(\pi_{t+1}^{-1} c_{t+1, s}^{-\sigma_{1}}\right)
\end{gathered}
$$

and

$$
m_{t, s}=(\chi \beta)^{1 / \sigma_{2}}\left(\frac{\left(1-R_{t}^{-1}\right) c_{t, s}^{-\sigma_{1}}}{E_{t, s} \pi_{t+1}^{\sigma_{2}-1}}\right)^{-1 / \sigma_{2}},
$$

where $\pi_{t+1, s}=P_{t+1, s} / P_{t, s}$. We now make use of the representative agent assumption. In the representative-agent economy all agents $s$ have the same utility functions, initial money and debt holdings and prices. We assume also that they make the same forecasts $E_{t, s} c_{t+1, s} E_{t, s} \pi_{t+1, s}, E_{t, s} \pi_{t+1}$, as well as forecasts of other variables that will become relevant below. Under these assumptions all agents make the same decisions at each point in time, so that $h_{t, s}=h_{t}, y_{t, s}=y_{t}, c_{t, s}=c_{t}$ and $\pi_{t, s}=\pi_{t}$, and all agents make the same forecasts. Imposing also the equilibrium condition $Y_{t}=y_{t}=h_{t}^{\alpha}$, one obtains the equations

$$
\begin{gathered}
\frac{\alpha \gamma}{\nu}\left(\pi_{t}-1\right) \pi_{t}=h_{t}\left(h_{t}^{\varepsilon}-\alpha\left(1-\frac{1}{\nu}\right) h_{t}^{\alpha-1} c_{t}^{-\sigma_{1}}\right)+\beta \frac{\alpha \gamma}{\nu} E_{t}\left[\left(\pi_{t+1}-1\right) \pi_{t+1}\right] \\
c_{t}^{-\sigma_{1}}=\beta R_{t} E_{t}\left(\pi_{t+1}^{-1} c_{t+1}^{-\sigma_{1}}\right) \\
m_{t}=(\chi \beta)^{1 / \sigma_{2}}\left(\frac{\left(1-R_{t}^{-1}\right) c_{t}^{-\sigma_{1}}}{E_{t} \pi_{t+1}^{\sigma_{2}-1}}\right)^{-1 / \sigma_{2}}
\end{gathered}
$$

For convenience, we make the assumptions $\sigma_{1}=\sigma_{2}=1$, i.e. utility of consumption and of money is logarithmic. It is also assumed that agents 
have point expectations, so that their decisions depend only on the mean of their subjective forecasts. This is a satisfactory assumption provided the shocks are sufficiently small. This allows us to write the system as

$$
\begin{gathered}
m_{t}=\chi \beta\left(1-R_{t}^{-1}\right)^{-1} c_{t} \\
c_{t}^{-1}=\beta r_{t+1}^{e}\left(c_{t+1}^{e}\right)^{-1}, \text { where } r_{t+1}^{e}=R_{t} / \pi_{t+1}^{e}, \text { and } \\
\frac{\alpha \gamma}{\nu}\left(\pi_{t}-1\right) \pi_{t}=h_{t}\left(h_{t}^{\varepsilon}-\alpha\left(1-\frac{1}{\nu}\right) h_{t}^{\alpha-1} c_{t}^{-1}\right)+\beta \frac{\alpha \gamma}{\nu}\left[\left(\pi_{t+1}^{e}-1\right) \pi_{t+1}^{e}\right] .
\end{gathered}
$$

Equation (12) is the nonlinear New Keynesian Phillips curve, which describes the optimal price-setting by firms. The term $\left(\pi_{t}-1\right) \pi_{t}$ arises from the quadratic form of the adjustment costs, and this expression is increasing in $\pi_{t}$ over the allowable range $\pi_{t} \geq 1 / 2$. To interpret this equation, note that the bracketed expression in the first term on the right-hand side is the difference between the marginal disutility of labor and the product of the marginal revenue from an extra unit of labor with the marginal utility of consumption. The terms involving current and future inflation arise from the price-adjustment costs resulting from marginal variations in labor supply. Equation (11) is the standard Euler equation giving the intertemporal first-order condition for the consumption path. Equation (10) is the money demand function resulting from the presence of real balances in the utility function. Note that for our parameterization, the demand for real balances becomes infinite as $R_{t} \rightarrow 1$.

We now proceed to rewrite the decision rules for $c_{t}$ and $\pi_{t}$ so that they depend on forecasts of key variables over the infinite horizon.

\subsection{The infinite-horizon Phillips curve}

We start with an infinite-horizon version of the Phillips curve (12). Let

$$
Q_{t}=\left(\pi_{t}-1\right) \pi_{t}
$$

The appropriate root for given $Q$ is $\pi \geq \frac{1}{2}$ and so we need to impose $Q \geq$

$-\frac{1}{4}$ to have a meaningful model. Making use of the aggregate relationships $h_{t}=y_{t}^{1 / \alpha}$ and $c_{t}=y_{t}-g_{t}$ we can rewrite (12) as

$$
Q_{t}=\frac{\nu}{\alpha \gamma} y_{t}^{(1+\varepsilon) / \alpha}-\frac{\nu-1}{\gamma} y_{t}^{\alpha}\left(y_{t}-g_{t}\right)^{-1}+\beta Q_{t+1}^{e} .
$$


Solving this forward we obtain

$$
Q_{t}=\frac{\nu}{\gamma} \sum_{j=0}^{\infty} \alpha^{-1} \beta^{j}\left(y_{t+j}^{e}\right)^{(1+\varepsilon) / \alpha}-\frac{\nu-1}{\gamma} \sum_{j=0}^{\infty} \beta^{j}\left(\frac{y_{t+j}^{e}}{x_{t+j}^{e}}\right) .
$$

Here $x_{t+j}^{e}$ denotes expected net output, which equals expectations of $y_{t+j}-$ $g_{t+j}$. The expectations are formed at time $t$ and variables at time $t$ are assumed to be in the information set of the agents. We will treat (14), together with (13), as the temporary equilibrium equations that determine $\pi_{t}$, given expectations $\left\{y_{t+j}^{e}, x_{t+j}^{e}\right\}_{j=1}^{\infty}$.

In the Phillip's curve relationship (14) one might wonder why inflation does not also depend directly on the expected future aggregate inflation rate. ${ }^{6}$ Equation (9) is obtained from the first-order conditions using (3) to eliminate relative prices. Because of the representative agent assumption, each firm's output equals average output in every period. Since firms can be assumed to have learned this is the case, we obtain (14). An alternative procedure would be to start from (9), iterate it forward and use the demand function to write the third term on the right-hand side of (9) in terms of the relative price. This would lead to a modification of (14) in which future relative prices also appear, but using the representative agent assumption, the relative price term would drop out.

\subsection{The consumption function}

To derive the consumption function from (11) we use the flow budget constraint and the NPG (no Ponzi game) to obtain an intertemporal budget constraint. Write

$$
b_{t}=r_{t} b_{t-1}+\Phi_{t}
$$

where $r_{t}=R_{t-1} / \pi_{t}$ and

$$
\Phi_{t}=y_{t}+m_{t-1} \pi_{t}^{-1}-c_{t}-m_{t}-\Upsilon_{t}
$$

Note that we assume $\left(P_{j t} / P_{t}\right) y_{j t}=y_{t}$, i.e. the representative agent assumption is being invoked. Iterating (15) forward and imposing

$$
\lim _{j \rightarrow \infty}\left(D_{t, t+j}^{e}\right)^{-1} b_{t+j}=0
$$

\footnotetext{
${ }^{6}$ There is an indirect effect of expected inflation on current inflation via current output.
} 
we obtain the life-time budget constraint of the household

$$
0=r_{t} b_{t-1}+\Phi_{t}+\sum_{j=1}^{\infty}\left(D_{t, t+j}^{e}\right)^{-1} \Phi_{t+j}^{e}
$$

where

$$
D_{t, t+j}^{e}=\prod_{i=1}^{j} r_{t+i}^{e}
$$

with $r_{t+j}^{e}=R_{t+j-1} / \pi_{t+j}^{e}$ and

$$
\Phi_{t+j}^{e}=y_{t+j}^{e}+m_{t+j-1}^{e}\left(\pi_{t+j}^{e}\right)^{-1}-c_{t+j}^{e}-m_{t+j}^{e}-\Upsilon_{t+j}^{e} .
$$

Here all expectations are formed in period $t$, which is indicated in the notation for $D_{t, t+j}^{e}$ but is omitted from the other expectational variables.

The consumption Euler equation (11) implies that

$$
c_{t+j}^{e}=c_{t} \beta^{j} D_{t, t+j}^{e} .
$$

Substituting this expression for $c_{t+j}^{e}$ in (18) it follows that

$$
0=r_{t} b_{t-1}-\sum_{j=0}^{\infty} c_{t} \beta^{j}+\phi_{t}+\sum_{j=1}^{\infty}\left(D_{t, t+j}^{e}\right)^{-1} \phi_{t+j}^{e}
$$

where

$$
\begin{aligned}
\phi_{t} & =y_{t}+m_{t-1} \pi_{t}^{-1}-m_{t}-\Upsilon_{t}, \\
\phi_{t+j}^{e} & =y_{t+j}^{e}+m_{t+j-1}^{e}\left(\pi_{t+j}^{e}\right)^{-1}-m_{t+j}^{e}-\Upsilon_{t+j}^{e} .
\end{aligned}
$$

A crucial issue is how households form expectations of future taxes. In this paper we make the strong Ricardian equivalence assumption that households understand that the government's intertemporal budget constraint will be satisfied. ${ }^{7}$ First, write down the latter constraint. From (4) one has

$$
\begin{aligned}
b_{t}+m_{t}+\Upsilon_{t} & =g_{t}+m_{t-1} \pi_{t}^{-1}+r_{t} b_{t-1} \text { or } \\
b_{t} & =\Delta_{t}+r_{t} b_{t-1} \text { where } \\
\Delta_{t} & =g_{t}-\Upsilon_{t}-m_{t}+m_{t-1} \pi_{t}^{-1} .
\end{aligned}
$$

\footnotetext{
${ }^{7}$ Relaxing this assumption would be of interest. This would require agents to forecast future taxes and the evolution of public debt. For a simple example of this approach see Evans, Honkapohja, and Mitra (2009).
} 
By forward substitution, and assuming $\lim _{T \rightarrow \infty} D_{t, t+T} b_{t+T}=0$,

$$
0=r_{t} b_{t-1}+\Delta_{t}+\sum_{j=1}^{\infty} D_{t, t+j}^{-1} \Delta_{t+j}
$$

Note that $\Delta_{t+j}$ is the primary government deficit in $t+j$, measured as government purchases less lump-sum taxes and less seigniorage. Under the Ricardian Equivalence assumption, we assume that agents at each time $t$ expect this constraint to be satisfied, i.e.

$$
\begin{aligned}
0 & =r_{t} b_{t-1}+\Delta_{t}+\sum_{j=1}^{\infty}\left(D_{t, t+j}^{e}\right)^{-1} \Delta_{t+j}^{e}, \text { where } \\
\Delta_{t+j}^{e} & =g_{t+j}^{e}-\Upsilon_{t+j}^{e}-m_{t+j}^{e}+m_{t+j-1}^{e}\left(\pi_{t+j}^{e}\right)^{-1} \text { for } j=1,2,3, \ldots .
\end{aligned}
$$

Substituting out $r_{t} b_{t-1}$ from (19) and rearranging we get

$$
(1-\beta)^{-1} c_{t}=\left(\phi_{t}-\Delta_{t}\right)+\sum_{j=1}^{\infty}\left(D_{t, t+j}^{e}\right)^{-1}\left(\phi_{t+j}^{e}-\Delta_{t+j}^{e}\right)
$$

or

$$
c_{t}=(1-\beta)\left(y_{t}-g_{t}+\sum_{j=1}^{\infty}\left(D_{t, t+j}^{e}\right)^{-1} x_{t+j}^{e}\right) .
$$

Equation (21) is viewed as the temporary equilibrium equation that, under Ricardian Equivalence, determines consumption, given expectations. In the inflation equation (14) it is assumed that households form $\left\{x_{t+j}^{e}\right\}_{j=1}^{\infty}$ and $\left\{y_{t+j}^{e}\right\}_{j=1}^{\infty}$ using an adaptive learning rule that treats these aggregates as an exogenously given process. For the consumption function (21) one needs also to specify how private agents form the discount factors $D_{t, t+j}^{e}=\prod_{i=1}^{j} r_{t+i}^{e}$. Various assumptions are natural, but we will focus on the assumption that $r_{t+i}^{e}$ is obtained from separate forecasts of inflation and interest rates, making use of the monetary policy rule to forecast the latter. Thus, monetary policy is both transparent and credible in that agents incorporate the interest rate rule in their expectations formation for all future periods. ${ }^{8}$ In this case,

\footnotetext{
${ }^{8}$ Alternatively, if the policy rule is not known to the agents, one could assume that agents forecast future real interest rates directly using an adaptive learning rule. The local stability results given below would continue to hold.
} 
combining $r_{t+j}^{e}(t)=R_{t+j-1}^{e} / \pi_{t+j}^{e}$ and $R_{t}=1+f\left(\pi_{t+1}^{e}\right)$ one obtains

$$
D_{t, t+j}^{e}=\prod_{i=1}^{j}\left(1+f\left(\pi_{t+j}^{e}\right)\right) / \pi_{t+j}^{e} .
$$

We remark that our consumption function (21) exhibits Ricardian Equivalence in the following sense:

Proposition 1 Household consumption depends on the sequence of expected government spending but not in any way on how it is financed.

This temporary equilibrium result for arbitrary subjective expectations generalizes the results of Wallace (1981) and Eggertsson and Woodford (2003), which presume that the RE hypothesis holds. The assumption of Ricardian consumers has, in particular, the implication that an open-market operation altering the initial composition of wealth between money and bonds has no effect on consumption, given subsequent interest rate policy and the sequence of government spending. In addition, the standard result about the neutrality of changes in lump-sum taxes holds in our setting.

\section{Learning and Stability of Steady States}

Consider first the steady states of the model. These are found by setting the random shocks to zero and setting $\pi_{t+j}^{e}=\pi_{t}=\pi, y_{t+j}^{e}=y_{t}=y$, and $x_{t+j}^{e}=y_{t+j}^{e}-\bar{g}=y-\bar{g}$. For any steady state $\pi$, equation (11) implies that the nominal interest rate factor satisfies the Fisher equation

$$
R=\beta^{-1} \pi
$$

As emphasized by Benhabib, Schmitt-Grohe, and Uribe (2001), because $f($. is nonnegative, continuous (and differentiable) and has a steady state $\pi^{*}$ with $f^{\prime}\left(\pi^{*}\right)>\beta^{-1}$, there must be a second steady state $\pi_{L}<\pi^{*}$ with $f^{\prime}\left(\pi_{L}\right)<$ $\beta^{-1}$. For our parametrization of $f(\cdot)$, there are no steady states other than the intended steady state $\pi^{*}$ and the unintended low-inflation steady state $\pi_{L}$. Figure 1 illustrates the two steady states resulting from the global Taylor rule subject to the zero lower bound on net interest rates. ${ }^{9}$

\footnotetext{
${ }^{9}$ We remark that it follows from Benhabib, Schmitt-Grohe, and Uribe (2001) and Evans, Guse, and Honkapohja (2008) that $\pi^{*}$ is locally determinate and $\pi_{L}$ is locally indeterminate under RE.
} 


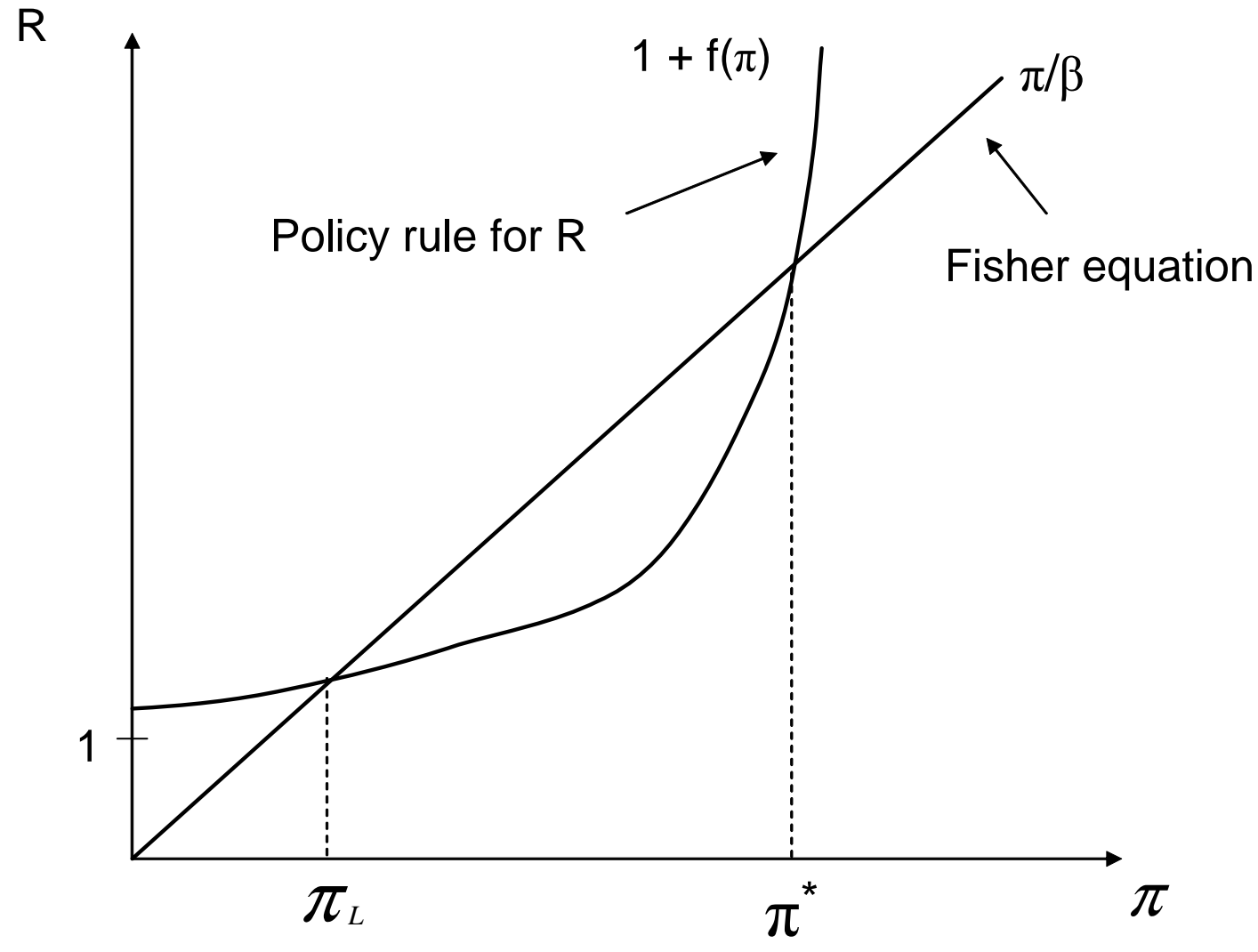

Figure 1: Multiple steady states under normal policy.

The other steady-state equations are given by

$$
\begin{gathered}
c=h^{\alpha}-\bar{g}, \\
-h^{1+\varepsilon}+\frac{\alpha \gamma}{\nu}(1-\beta)(\pi-1) \pi+\alpha\left(1-\frac{1}{\nu}\right) h^{\alpha} c^{-1}=0
\end{gathered}
$$

and a steady-state version of (10). It is shown in the Appendix of Evans, Guse, and Honkapohja (2008) that in most cases there is a corresponding unique interior steady state $c>0$ and $h>0$.

The starting point in the learning approach to expectations formation is that economic agents have very limited knowledge about the structure of the economy, so that they do not have RE and instead make inference about the relevant parts of the economy that they need for forecasting. The agents make 
forecasts using a reduced-form econometric model of the relevant variables and using parameters that are estimated using past data. The forecasts are input to agent's decision rules and in each period the economy attains a temporary equilibrium, i.e., an equilibrium for the current period variables given the forecasts of the agents. See e.g. Evans and Honkapohja (2001), Sargent (2008) and Evans and Honkapohja (2009) for general discussions of adaptive learning.

The temporary equilibrium provides a new data point, which in the next period leads to re-estimation of the parameters and updating of the forecasts and, in turn, to a new temporary equilibrium. The sequence of temporary equilibria may generate parameter estimates that converge to a fixed point corresponding to an RE equilibrium for the economy. When the convergence takes place, we say that the RE equilibrium is stable under learning. In the general formulation of the model given above, it was assumed that the economy is subject to stationary autoregressive random shocks. If these exogenous shocks are observable, then agents would naturally include them in their forecasting model, and the coefficients of the model would be estimated and updated by an econometric technique such as recursive least squares. If the exogenous shocks are iid then they provide no information about their future values and thus would be excluded from the forecasting model. In this case agents would simply estimate the intercept for each variable. If these estimates converge over time to fixed values, the limit corresponds to a $\mathrm{RE}$ stochastic steady state. In the current model there are two possible RE stochastic steady states. When the random shocks are small these are close to the nonstochastic steady states discussed above.

The simple set-up just described, in which only intercepts are estimated, is referred to as "steady-state learning." More specifically, steady-state learning with point expectations is formalized as

$$
y_{t+j}^{e}=y_{t}^{e} \text { and } \pi_{t+j}^{e}=\pi_{t}^{e} \text { for all } j \geq 1 \text {. }
$$

and

$$
z_{t}^{e}=z_{t-1}^{e}+\omega_{t}\left(z_{t-1}-z_{t-1}^{e}\right)
$$

for $z=y, \pi$. Here $\omega_{t}$ is called the "gain sequence," and measures the extent of adjustment of estimates to the most recent forecast error. In stochastic systems one often sets $\omega_{t}=t^{-1}$ and this "decreasing gain" learning corresponds to least-squares updating. Also widely used is the case $\omega_{t}=\omega$, for $0<\omega \leq 1$, called "constant gain" learning. In this case it is usually assumed 
that $\omega$ is small. Stability of the steady states is examined below using the simple learning rules just described. Thus the exogenous random shocks are assumed to be iid. This is merely a simplification since it can be shown that the stability of the steady states is governed by the stability of the estimates of the intercepts. Furthermore, it can also be shown that provided the iid shocks are sufficiently small, the stability properties of steady states are the same as for the corresponding nonstochastic system. Thus, for simplicity, in what follows the exogenous shocks $\theta_{t}, u_{t}, \eta_{t}$ are assumed to be constants, equal to their respective mean values, and we study steady state learning within the nonstochastic system.

\subsection{Temporary equilibrium}

Collecting the preceding, the following equations define the temporary equilibrium under normal policy.

1) Phillips curve

$$
\begin{aligned}
Q_{t} & =\frac{\nu}{\gamma} \sum_{j=0}^{\infty} \alpha^{-1} \beta^{j}\left(y_{t+j}^{e}\right)^{(1+\varepsilon) / \alpha}-\frac{\nu-1}{\gamma} \sum_{j=0}^{\infty} \beta^{j}\left(\frac{y_{t+j}^{e}}{y_{t+j}^{e}-\bar{g}}\right) \\
Q_{t} & =\left(\pi_{t}-1\right) \pi_{t} .
\end{aligned}
$$

2) Consumption function

$$
\begin{aligned}
c_{t} & =(1-\beta)\left(y_{t}-g_{t}+\sum_{j=1}^{\infty}\left(D_{t, t+j}^{e}\right)^{-1}\left(y_{t+j}^{e}-\bar{g}\right)\right), \\
D_{t, t+j}^{e} & =\prod_{i=1}^{j}\left(1+f\left(\pi_{t+i}^{e}\right)\right) / \pi_{t+i}^{e} .
\end{aligned}
$$

3) Money demand

$$
m_{t}=\chi \beta\left(1-R_{t}^{-1}\right)^{-1} c_{t} .
$$

4) Government budget constraint

$$
b_{t}+m_{t}+\kappa_{0}+\kappa b_{t-1}=\bar{g}+m_{t-1} \pi_{t}^{-1}+R_{t-1} \pi_{t}^{-1} b_{t-1} .
$$

5) The interest-rate rule

$$
R_{t}-1=f\left(\pi_{t+1}^{e}\right)
$$


where

$$
f(\pi)=\left(R^{*}-1\right)\left(\frac{\pi}{\pi^{*}}\right)^{A R^{*} /\left(R^{*}-1\right)} .
$$

6) Market clearing

$$
y_{t}=c_{t}+\bar{g}
$$

Given expectations $\left\{y_{t+j}^{e}, \pi_{t+j}^{e}\right\}_{j=1}^{\infty}$, the above six equations define the temporary equilibrium in $c_{t}, \pi_{t}, y_{t}, R_{t}, m_{t}, b_{t}$. The model dynamics are then completed by specifying the evolution of expectations over time in accordance with the learning rules described above. The dynamics under learning can be conveniently described by using the close connection between the possible convergence of least-squares learning to an RE equilibrium and a stability condition, known as E-stability. E-stability of an equilibrium is based on a mapping from the perceived law of motion that private agents are estimating and using to make forecasts to the implied actual law of motion generating the data (i.e. the temporary equilibrium) under these perceptions. E-stability is defined in terms of local stability, at an RE equilibrium, of a differential equation based on this map. For a general discussion of adaptive learning and the E-stability principle see Evans and Honkapohja (2001).

Before turning to the E-stability results, we briefly discuss the issue of the transversality conditions in our temporary equilibrium set-up. Under steadystate learning, $\pi_{t+j}^{e}=\pi_{t}^{e}$ for all $j \geq 1$ implies $D_{t, t+j}^{e}=\left(\left(1+f\left(\pi_{t}^{e}\right)\right) / \pi_{t}^{e}\right)^{j}=$ $\left(r_{t}^{e}\right)^{j}$, where $r_{t}^{e}=\left(1+f\left(\pi_{t}^{e}\right)\right) / \pi_{t}^{e}$ is the expected real interest factor, and the consumption function takes the form

$$
c_{t}=(1-\beta)\left(y_{t}-\bar{g}+\frac{1}{r_{t}^{e}-1}\left(y_{t}^{e}-\bar{g}\right)\right) .
$$

provided $r_{t}^{e}>1 .{ }^{10}$ The consumption function gives the time $t$ choice of consumption based on information and forecasts at time $t$, and can be viewed as the first step of an infinite-horizon dynamic plan. From the consumption Euler equation it follows that the expected path of future consumption (with $\sigma_{1}=1$ ) is given by

$$
c_{t+j}^{-1}=\left(r_{t}^{e}\right)^{-j} \beta^{-j} c_{t}^{-1}, \text { for } j=1,2,3, \ldots,
$$

where here $c_{t+j}^{-1}$ is the expected marginal utility of money at $t+j$. The relevant transversality condition for the household is that

$$
\lim _{j \rightarrow \infty} c_{t+j}^{-1} \beta^{j} b_{t+j}=0
$$

\footnotetext{
${ }^{10}$ See the discussion below for our treatment of the case $r_{t}^{e} \leq 1$.
} 
holds along the planned path of consumption and bonds. Because the consumption function is derived using the intertemporal budget constraint obtained using the NPG condition, we know that the condition

$$
\lim _{j \rightarrow \infty}\left(D_{t, t+j}^{e}\right)^{-1} b_{t+j}=\lim _{j \rightarrow \infty}\left(r_{t}^{e}\right)^{-j} b_{t+j}=0
$$

is satisfied. Since, using the consumption Euler equation, we have $c_{t+j}^{-1} \beta^{j} b_{t+j}=$ $\left(r_{t}^{e}\right)^{-j} c_{t}^{-1} b_{t+j}$, it follows that (28) is satisfied along the planned path. ${ }^{11}$ Thus, at each point in time, the transversality condition is met for the households' planned path of consumption and wealth.

\section{$3.2 \quad$ E-Stability}

The theoretical results for learning below are based on E-stability analysis of the system under the learning rules (26). It can be shown that a steady state is locally stable under learning for decreasing or small constant gains if and only if it is E-stable. ${ }^{12}$ The definition of E-stability for the case at hand is given below.

We now proceed to the analysis of E-stability of the two possible steady states when the global interest rate rule (8) describes monetary policy. Using (27) and market clearing,

$$
\begin{aligned}
y_{t} & =\bar{g}+\left(\beta^{-1}-1\right)\left(y_{t}^{e}-\bar{g}\right)\left(\frac{\pi_{t}^{e}}{1+f\left(\pi_{t}^{e}\right)-\pi_{t}^{e}}\right) \\
& \equiv G_{1}\left(y_{t}^{e}, \pi_{t}^{e}\right) .
\end{aligned}
$$

Temporary equilibrium is given by equations (29) and

$$
\pi_{t}=Q^{-1}\left[K\left(G_{1}\left(y_{t}^{e}, \pi_{t}^{e}\right), y_{t}^{e}\right)\right] \equiv G_{2}\left(y_{t}^{e}, \pi_{t}^{e}\right)
$$

\footnotetext{
${ }^{11}$ Using the money demand equation it follows that $\lim _{j \rightarrow \infty} m_{t+j}^{-1} \beta^{j} b_{t+j}=0$ also holds along the planned path.

${ }^{12}$ See Evans and Honkapohja (2001), Evans and Honkapohja (2009) for general discussions of E-stability. Sections 3.3-3.4, 7.2 and chapter 11 of Evans and Honkapohja (2001) discuss the special case of steady-state learning.
} 
where

$$
\begin{aligned}
Q\left(\pi_{t}\right) \equiv & \left(\pi_{t}-1\right) \pi_{t} \\
K\left(y_{t}, y_{t}^{e}\right) \equiv & \frac{\nu}{\gamma}\left(\alpha^{-1} y_{t}^{(1+\varepsilon) / \alpha}-\left(1-\nu^{-1}\right) \frac{y_{t}}{\left(y_{t}-\bar{g}\right)}\right) \\
& +\frac{\nu}{\gamma}\left(\beta(1-\beta)^{-1}\left(\alpha^{-1}\left(y_{t}^{e}\right)^{(1+\varepsilon) / \alpha}-\left(1-\nu^{-1}\right) \frac{y_{t}^{e}}{\left(y_{t}^{e}-\bar{g}\right)}\right)\right) .
\end{aligned}
$$

The E-stability equations are

$$
\begin{aligned}
\frac{d y^{e}}{d \tau} & =G_{1}\left(y^{e}, \pi^{e}\right)-y^{e} \\
\frac{d \pi^{e}}{d \tau} & =G_{2}\left(y^{e}, \pi^{e}\right)-\pi^{e} .
\end{aligned}
$$

By construction, the steady states are fixed points of this system of differential equations. A steady state is said to be E-stable if it is locally stable under (32). The differential equations operate in "notional" or "virtual" time. It can be shown that for large values of the (discrete) real time $t$, the continuous time paths $\left(y^{e}(\tau), \pi^{e}(\tau)\right)$ of $(32)$ are approximately related to the discrete-time trajectories $\left(y_{t}^{e}, \pi_{t}^{e}\right)$ of $(26)$ at specific points of real time: $\left(y^{e}\left(t_{n}\right), \pi^{e}\left(t_{n}\right)\right) \approx\left(y_{n}^{e}, \pi_{n}^{e}\right)$ for $t_{n}=\sum_{i=1}^{n} \omega_{i}$.

To examine local stability of a steady state $(\bar{\pi}, \bar{y})$, one calculates the Jacobian

$$
D G I=\left(\begin{array}{cc}
D_{y^{e}} G_{1}-1 & D_{\pi^{e}} G_{1} \\
D_{y^{e}} G_{2} & D_{\pi^{e}} G_{2}-1
\end{array}\right) .
$$

Starting with function $G_{2}$, take differentials

$$
\begin{aligned}
D_{y^{e}} G_{2} & =\left(Q^{-1}\right)^{\prime}\left(K_{y} D_{y^{e}} G_{1}+K_{y^{e}}\right)>0 \\
D_{\pi^{e}} G_{2} & =\left(Q^{-1}\right)^{\prime} K_{y} D_{\pi^{e}} G_{1} .
\end{aligned}
$$

The various derivatives at a steady state are:

$$
\begin{gathered}
\left(Q^{-1}\right)^{\prime}=\frac{1}{2 \bar{\pi}-1}>0 \\
K_{y}=\frac{\nu}{\gamma}\left((1+\varepsilon) y^{\frac{1+\varepsilon+\alpha}{\alpha}}+\left(1-\nu^{-1}\right) \frac{\bar{g}}{(y-\bar{g})^{2}}\right)>0
\end{gathered}
$$




$$
K_{y^{e}}=\frac{\nu}{\gamma} \frac{\beta}{1-\beta}\left((1+\varepsilon) y^{\frac{1+\varepsilon+\alpha}{\alpha}}+\left(1-\nu^{-1}\right) \frac{\bar{g}}{(y-\bar{g})^{2}}\right)>0 .
$$

One also needs to compute the following partial derivatives at a steady state:

$$
\begin{aligned}
& D_{y^{e}} G_{1}=\left(\beta^{-1}-1\right)\left(\frac{\bar{\pi}}{1+f(\bar{\pi})-\bar{\pi}}\right)=1 \\
& D_{\pi^{e}} G_{1}=\left(\beta^{-1}-1\right)(\bar{y}-\bar{g})\left(\frac{1+f(\bar{\pi})-\bar{\pi} f^{\prime}(\bar{\pi})}{(1+f(\bar{\pi})-\bar{\pi})^{2}}\right) .
\end{aligned}
$$

Here $1+f(\bar{\pi})-\bar{\pi} f^{\prime}(\bar{\pi})=\left(\beta^{-1}-f^{\prime}(\bar{\pi})\right) \bar{\pi}$, which is negative at $\pi^{*}$ and positive at $\pi_{L}$. Thus,

$$
D_{\pi^{e}} G_{1}<0 \text { at } \pi^{*} \text { and }>0 \text { at } \pi_{L} .
$$

For the sign of $D_{\pi^{e}} G_{2}$ we have

$$
\operatorname{sgn}\left[D_{\pi^{e}} G_{2}\right]=\operatorname{sgn}\left[D_{\pi^{e}} G_{1}\right]
$$

It follows that the Jacobian at the normal steady state $\pi^{*}$ is

$$
D G I=\left(\begin{array}{cc}
0 & - \\
+ & -
\end{array}\right)
$$

implying E-stability of $\pi^{*}$. At the low-inflation steady state $\pi_{L}$ the Jacobian is

$$
D G I=\left(\begin{array}{cc}
0 & + \\
+ & ?
\end{array}\right)
$$

The $(2,2)$ element is $D_{\pi^{e}} G_{2}-1$ and for sufficiently small $\gamma D_{\pi^{e}} G_{2}$ becomes large (see the expression for $K_{y}$ ), so the element is positive for small $\gamma$ which implies E-instability of $\pi_{L}$.

Collecting the results:

Proposition 2 The model with normal policy has two steady state states $\pi^{*}$ and $\pi_{L}$. Under infinite-horizon decision rules with steady-state learning the targeted steady state $\pi^{*}$ is locally stable under learning. For $\gamma$ sufficiently small the low-inflation steady state is locally unstable taking the form of a saddle point.

For global results we turn to numerical analysis. One technical issue has to be taken care of in connection with steady state learning by households. With arbitrary value of inflation expectations, there are regions of the space 
of expectations in which the expected real interest rate and thus $1+f\left(\pi_{t}^{e}\right)-\pi_{t}^{e}$ can be negative. This would imply infinite consumption in the preceding formula for the consumption function. To avoid this difficulty, truncate the steady-state expectations of the household at some long but finite horizon $T$ and postulate that beyond the horizon, agents just assume that real rate of interest has reached its steady state value $\beta^{-1}$. With this assumption the consumption function becomes

$$
c_{t}=(1-\beta)\left[y_{t}-\bar{g}+\left(y_{t}^{e}-\bar{g}\right)\left[\frac{\pi_{t}^{e}\left(1-\left(\frac{\pi_{t}^{e}}{1+f\left(\pi_{t}^{e}\right)}\right)^{T}\right)}{1+f\left(\pi_{t}^{e}\right)-\pi_{t}^{e}}+\frac{\beta^{T}}{\beta^{-1}-1}\right]\right]
$$

and so

$$
y_{t}=\bar{g}+\left(\beta^{-1}-1\right)\left(y_{t}^{e}-\bar{g}\right)\left[\frac{\pi_{t}^{e}\left(1-\left(\frac{\pi_{t}^{e}}{1+f\left(\pi_{t}^{e}\right)}\right)^{T}\right)}{1+f\left(\pi_{t}^{e}\right)-\pi_{t}^{e}}+\frac{\beta^{T}}{\beta^{-1}-1}\right] .
$$

In the global analysis one must also make sure that $\pi \geq 1 / 2$. This is achieved in the numerics by setting $\pi=1 / 2$ if the other temporary equilibrium equations would imply $Q<-\frac{1}{4}$.

Figure 2 illustrates the theoretical results in Proposition 2. The parameter values $A=2.5, \pi^{*}=1.02, \beta=0.99, \alpha=0.75, \beta=20, \nu=1.5, \varepsilon=1$, $R^{*}=\pi^{*} / \beta, \bar{g}=0.1$ and $T=50$ are used. The figure shows the phase diagram of the system (32) for the evolution of expectations under learning. Given expectations dynamics, it is easy to compute the trajectories of actual inflation and output. 


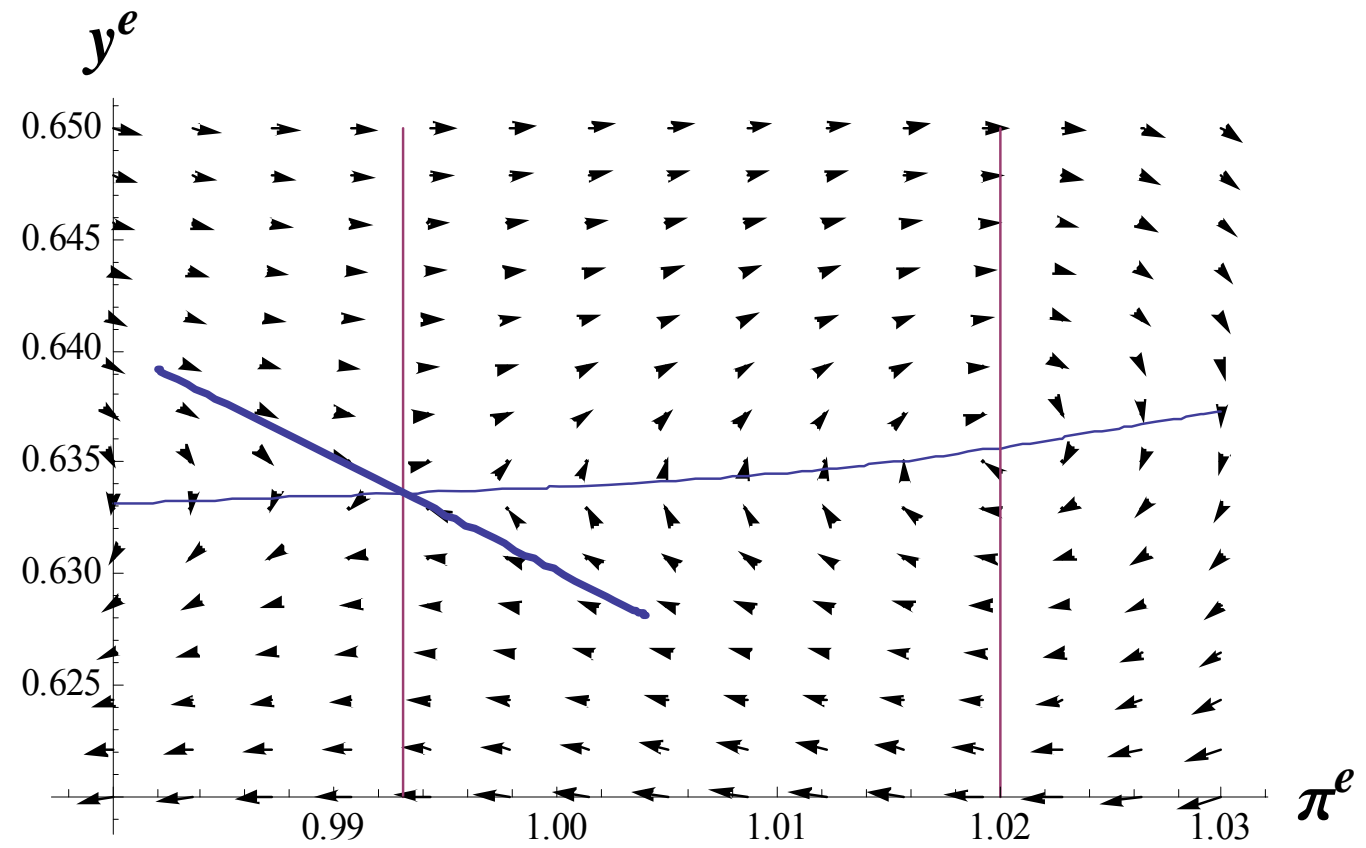

Figure 2: E-stability dynamics under global Taylor rule

Figure 2 shows the global E-stability dynamics that provide an approximation to the real-time dynamics of learning. Examining the aggregate demand equation (29), it is seen that the locus consisting of the two vertical lines gives values for $\left(\pi^{e}, y^{e}\right)$ at which $\frac{d y^{e}}{d \tau}=0$, while the upward-sloping curve gives values for $\left(\pi^{e}, y^{e}\right)$ at which $\frac{d \pi^{e}}{d \tau}=0$. The targeted steady state at $\pi^{*}=1.02$ is locally stable under E-stability dynamics and convergence toward it is cyclical. The low steady state $\pi_{L}=0.993092, y_{L}=0.633614$ is a saddle point and, most importantly, there is a region of initial expectations implying unstable trajectories with falling inflation expectations and eventually falling output expectations. The same holds true for actual inflation and output. We call these paths deflationary spirals and this region the deflationary trap. The downward-sloping line through the low steady state gives the local linear approximation of the stable manifold separating the basin of attraction of the targeted steady state from the deflationary region.

Figure 2 shows that the problem of deflationary traps for sufficiently pessimistic expectations, discovered in Evans, Guse, and Honkapohja (2008) for Euler equation learning, continues to arise under infinite-horizon learning, in which consumption, output and inflation are determined as the first-period 
decisions of the solution to the infinite-horizon optimization problem under subjective expectations based on our learning rule. The intuition for the unstable trajectories is that sufficiently pessimistic expectations $\pi_{t}^{e}$, $y_{t}^{e}$ lead to high expected real interest rates, because of the zero lower bound on net nominal interest rates. High expected real interest rates and low expected incomes, imply lower inflation and output through the consumption function and the infinite-horizon Phillips curve. The learning rule can then lead to a downward revision of expectations over time, pushing the economy further along an unstable trajectory. Of course, along an unstable path one would expect either private agents or policymakers eventually to alter their actions, but our results nonetheless indicate the potential for major disruptions to the economy resulting from large negative shocks to expectations. We now turn to possible policy changes that can avoid these undesirable outcomes.

\section{Alternative Monetary and Fiscal Policies}

\subsection{Monetary Policy Committing to Low Interest Rates}

In earlier work with Eran Guse, published as Evans, Guse, and Honkapohja (2008), we considered the implications of aggressive monetary easing triggered by inflation rates below some threshold $\tilde{\pi}$, where $\pi_{L}<\tilde{\pi}<\pi^{*}$. That paper studied Euler-equation learning in which agents have short horizons, and it was found that this type of policy did not provide a fool-proof way to avoid deflationary spirals. In the current framework agents have long horizons in their decision-making, so that there appears to be more scope for aggressive monetary policy to eliminate these unstable trajectories. Furthermore, in models with RE commitment to long periods of low interest rates has been advocated as a way to avoid the consequences of liquidity traps, see e.g. Krugman (1998), Eggertsson and Woodford (2003), and Svensson (2003).

We modify the interest rate rule to include aggressive monetary easing if expected inflation gets too low. This idea is formalized by introducing a lower threshold for inflation, so that the interest rate $R_{t}$ is cut to a low level $\hat{R}$ very close to one. To maintain continuity of the interest rate rule, one 
introduces two threshold values $\pi_{L}<\tilde{\pi}_{1}<\tilde{\pi}_{2}<\pi^{*}$ with $\tilde{\pi}_{1} \approx \tilde{\pi}_{2}$ and

$$
\tilde{f}\left(\pi^{e}\right)=R-1=\left\{\begin{array}{c}
f\left(\pi^{e}\right) \text { if } \pi^{e}>\tilde{\pi}_{2} \\
\hat{R}+\left(\pi^{e}-\tilde{\pi}_{1}\right) \frac{f\left(\tilde{\pi}_{2}\right)-\hat{R}}{\tilde{\pi}_{2}-\tilde{\pi}_{1}} \text { if } \tilde{\pi}_{1} \leq \pi^{e} \leq \tilde{\pi}_{2} \\
\hat{R} \text { if } \pi^{e}<\tilde{\pi}_{1}
\end{array}\right.
$$

so that $f\left(\pi^{e}\right)$ in the earlier rule (8) is replaced by $\tilde{f}\left(\pi^{e}\right)$.

Figure 3 illustrates the expectation dynamics with aggressive monetary easing. The numerics set $\tilde{\pi}_{1}=1.009$ and $\tilde{\pi}_{2}=1.01$, so that the interest rate is adjusted linearly down to $R=1.001 \equiv \hat{R}$. The other parameter values are unchanged. It is evident that the possibility of deflationary spirals remains. The new policy does help a little bit because it shifts the unstable region south-west, as is evident from comparing Figures 2 and 3. The constrained low steady-state values in Figure 3 are $\pi_{L}=0.99099, y_{L}=0.633459$, which are lower than the values of the low-inflation steady state in Figure 2. Our main point is that adding aggressive monetary easing at low (expected) inflation rates is not sufficient to eliminate the region of deflation traps.

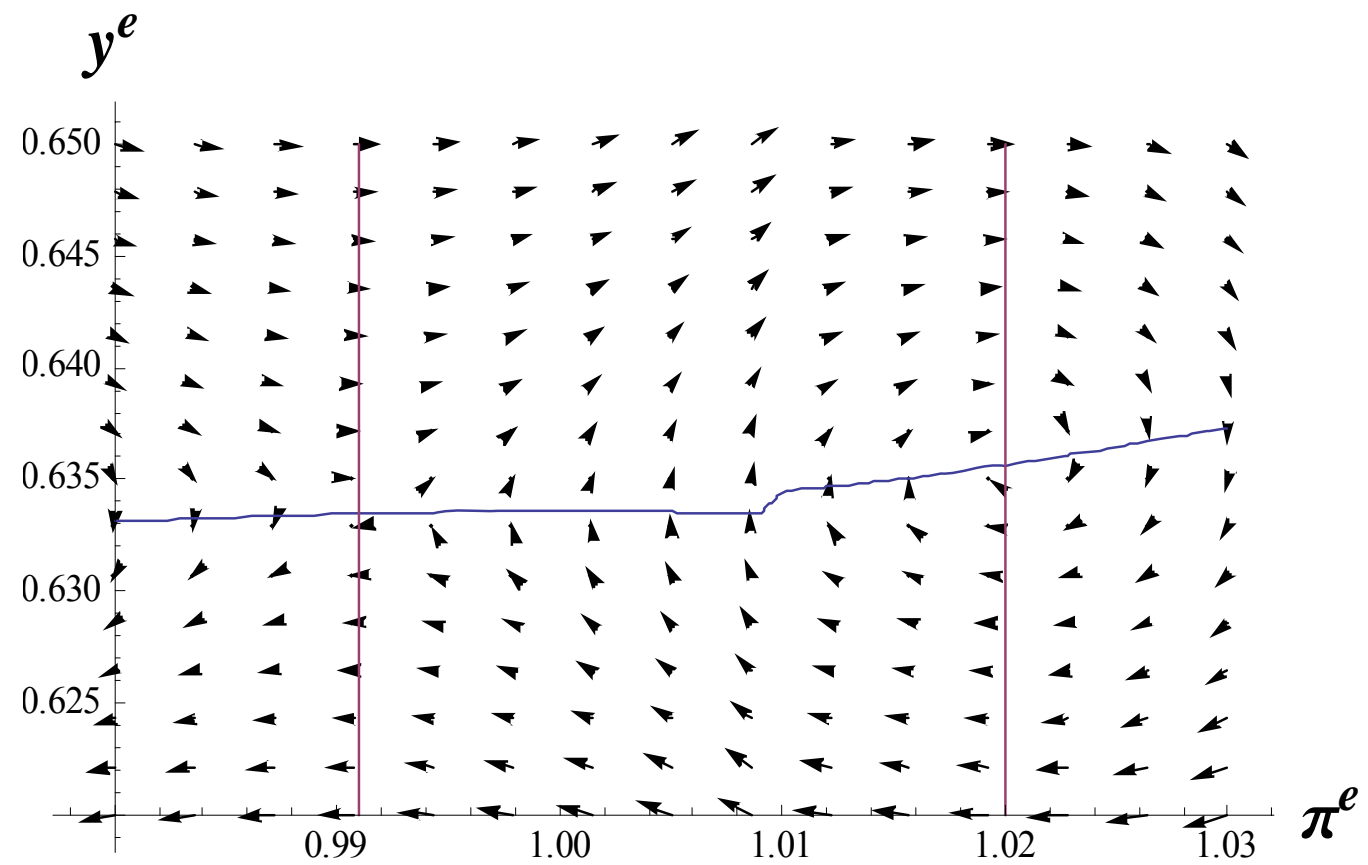

Figure 3: Global expectations dynamics with aggressive monetary easing 
In Figure 3 it is assumed that agents have incorporated the interest rate rule in their consumption function and thus they are assumed to know that aggressive monetary easing will be continued as long as inflation expectations remain low. We now take up the possibility that the central bank commits to zero interest rates for an extended period of time that continues even if inflation expectations increase toward the targeted value. This is investigated in our learning setup by considering the limit case in which policy makers respond to low inflation by committing to the zero interest-rate policy forever. Surprisingly, the possibility of deflation traps remains even in this extreme case of monetary easing forever. This result is illustrated in Figure 4.

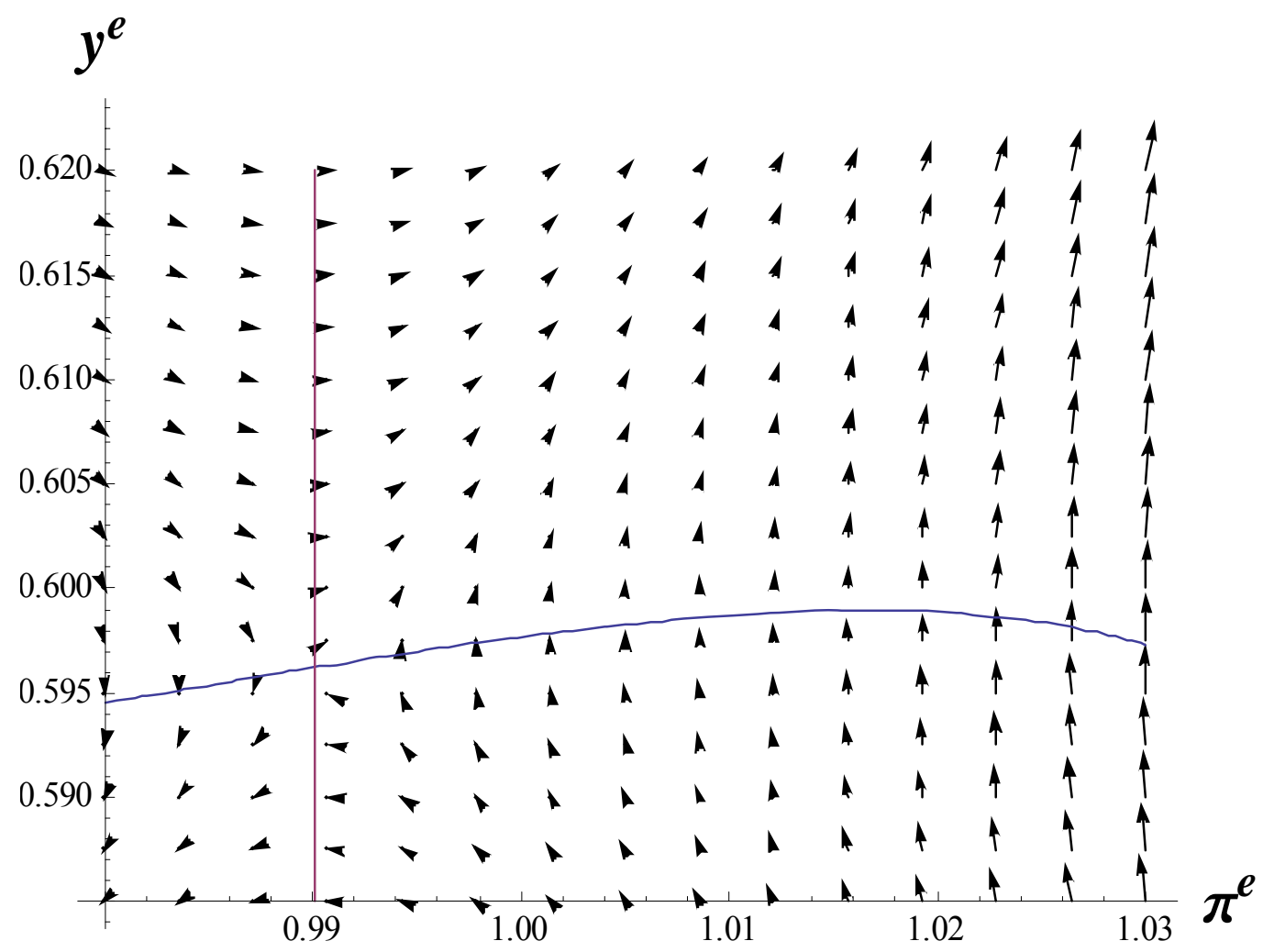

Figure 4: Dynamics with aggressive monetary easing forever

It can be seen that, for sufficiently pessimistic expectations, the region of deflation traps continues to exist. This policy reduces the deflationary region somewhat but at the great cost of converting the previous region of stability into a regime in which inflation would increase without bound. 


\subsection{Combined Monetary and Fiscal Easing}

We now add aggressive fiscal policy to the preceding monetary easing policy, following Evans, Guse, and Honkapohja (2008). The key idea is to temporarily increase government spending to ensure that inflation never falls below a suitable threshold. With changes in government spending, agents now have to forecast both gross and net output, which implies that the expectation dynamics become three-dimensional and phase diagrams cannot be conveniently used to illustrate the dynamics. Instead, selected time paths of central variables are plotted in the next two figures. The formal changes to the model are as follows.

First, assume that expectations of net output are determined by steadystate learning as was earlier done for output and inflation. Thus, in addition to (26) the expectation dynamics for $x_{t}^{e}$ are given by

$$
x_{t}^{e}=x_{t-1}^{e}+\omega_{t}\left(x_{t-1}-x_{t-1}^{e}\right) .
$$

The temporary equilibrium equations are now given by the following. Gross output is ${ }^{13}$

$$
\begin{aligned}
y_{t} & =g_{t}+\left(\beta^{-1}-1\right) x_{t}^{e} \sum_{j=1}^{\infty}\left(D_{t, t+j}^{e}\right)^{-1}, \\
D_{t, t+j}^{e} & =\left[\left(1+\tilde{f}\left(\pi_{t}^{e}\right)\right) / \pi_{t}^{e}\right]^{j} .
\end{aligned}
$$

Net output is given by

$$
x_{t}=y_{t}-g_{t}
$$

Evidently, for given expectations net output is independent of $g_{t}$, so that in temporary equilibrium the government spending multiplier is one. Inflation is determined by

$$
\begin{aligned}
Q\left(\pi_{t}\right) \equiv & \left(\pi_{t}-1\right) \pi_{t} \\
Q\left(\pi_{t}\right)= & \frac{\nu}{\gamma}\left(\alpha^{-1} y_{t}^{(1+\varepsilon) / \alpha}-\left(1-\nu^{-1}\right) \frac{y_{t}}{x_{t}}\right) \\
& +\frac{\nu}{\gamma}\left(\beta(1-\beta)^{-1}\left(\alpha^{-1}\left(y_{t}^{e}\right)^{(1+\varepsilon) / \alpha}-\left(1-\nu^{-1}\right) \frac{y_{t}^{e}}{x_{t}^{e}}\right)\right)
\end{aligned}
$$

\footnotetext{
${ }^{13}$ It should be noted that this equation holds only if $\left(1+\tilde{f}\left(\pi_{t}^{e}\right)\right) / \pi_{t}^{e}>1$ and this issue was dealt with by the truncation of the consumption function in the numerical analysis as explained earlier.
} 
These equations are a generalization of (30)-(31). ${ }^{14}$

The policy of fiscal easing is begun as triggered by actual inflation threatening to fall below the threshold $\tilde{\pi}_{1}$ specified in the modification to the interest rate rule in equation (33) in the preceding section. Specifically, it is assumed that if $\pi_{t}<\tilde{\pi}_{1}$ at $g_{t}=\bar{g}$ then government spending is increased to whatever level is needed to ensure $\pi_{t}=\tilde{\pi}_{1}$. This is feasible because of the following Lemma:

Lemma 3 For given expectations $\pi_{t}^{e}, y_{t}^{e}, x_{t}^{e}$,

$$
\frac{d \pi_{t}}{d g_{t}} \geq k
$$

for some $k>0$ and $g_{t}$ sufficiently large.

Proof. As net output is constant, we have $\frac{d y_{t}}{d g_{t}}=1$. Then, it is seen from (37)-(38) that $\frac{\partial Q}{\partial y_{t}}$ is bounded above zero for $y_{t}$ sufficiently large and so the same holds for $\frac{\partial \pi_{t}}{\partial y_{t}}$.

The Lemma implies that under our policy of combined fiscal and monetary easing triggered by the inflation threshold, inflation will never fall below $\tilde{\pi}_{1}$. We remark that this result holds regardless of the elasticity of labor supply, which is parameterized by $\varepsilon>0$. If $\varepsilon$ is large, so that labor supply is highly inelastic, then the sensitivity of inflation to output in the Phillips curve is correspondingly higher.

The lemma implies the following global uniqueness result:

Proposition 4 Consider the temporary equilibrium system (33), (34), (35), (36), (37) and (38) with fiscal easing triggered by the threshold $\tilde{\pi}_{1}$. There is a unique steady state with inflation at $\pi^{*}$ and a corresponding value for output, with $g_{t}=\bar{g}$. The targeted steady state is locally stable under learning.

Proof. From (34)-(35) in a steady state we obtain the Fisher equation $R=\beta^{-1} \pi$. The interest rate rule provides a second steady-state relationship $R=1+\tilde{f}(\pi)$. These equations have a unique solution at $\pi^{*}$ under the specified policy since the policy implies the restriction $\pi \geq \tilde{\pi}_{1}$. Local stability under learning follows from Proposition 2.

\footnotetext{
${ }^{14}$ As mentioned earlier, these equations hold provided that $Q\left(\pi_{t}\right)>-\frac{1}{4}$ and in this case $\pi_{t}$ is taken as the upper root of the quadratic. For $Q\left(\pi_{t}\right) \leq-\frac{1}{4}$ we set $\pi_{t}=\frac{1}{2}$.
} 
The numerical results indicate that the steady state is globally stable under learning.

The results are illustrated in Figures 5 and 6 . Consider a starting point $\pi^{e}=0.995, y^{e}=0.62$ and $x^{e}=0.52$, which is picked from the deflationary region in Figure 3. Figure 5 shows the time paths for expectations of inflation, output and net output. The ordering of the times from top to bottom is $\pi^{e}$, $y^{e}$ and $x^{e}$. While there are initial fluctuations in these expectations, the time paths converge to the targeted steady state over time. Figure 6 shows the corresponding dynamics of actual inflation, output and government spending. The ordering of curves from top down on the right is $\pi, y$ and $g$. It is seen that actual values of inflation and the output variables also converge to their steady state values after initial fluctuations. We remark that the time variable plotted here is notional time $\tau$ corresponding to the E-stability differential equation. For constant gains the link to real time $t$ depends on the "gain" $\omega$ of the learning rule according to $\tau=\omega t$. Thus if $\omega=0.10$ per quarter then $\tau=2$ corresponds to $t=20$ quarters.

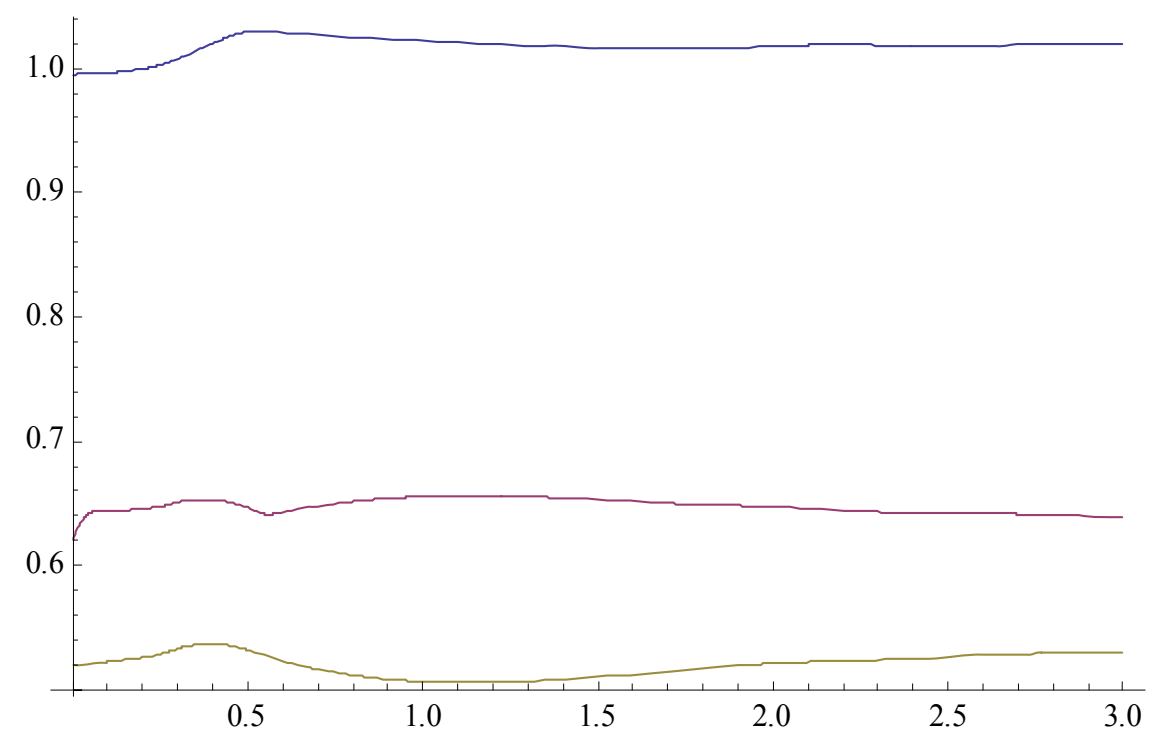

Figure 5: Inflation, output, and net output expectations over time 


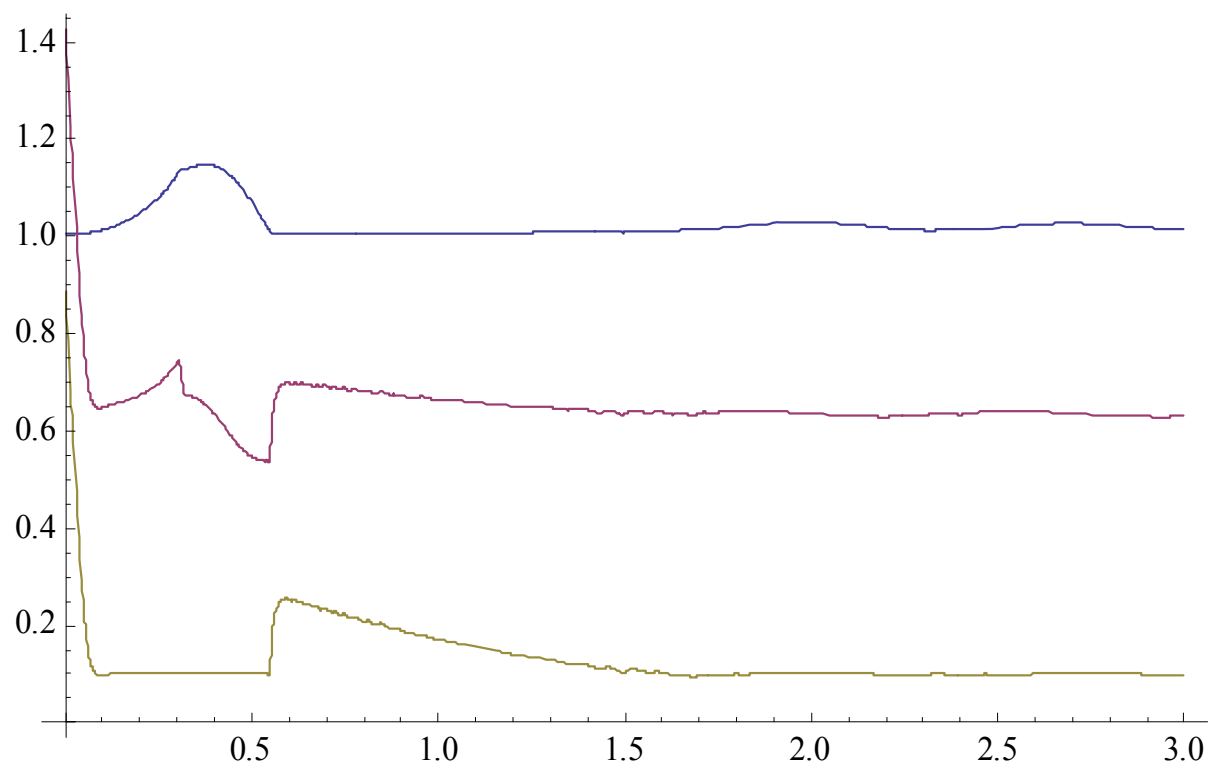

Figure 6: Time paths of actual inflation, output, and government spending

It evident that there is convergence to the unique steady state and this result appears to be robust numerically. Thus, this policy appears to provide a robust way to avoid a liquidity trap and the associated deflationary dynamics that arise with learning under the basic interest rate policy. The mechanism is that by stabilizing prices through expansionary government spending, low nominal interest rates yield low expected real interest rates, which leads to a recovery of private spending.

While our recommended policy does successfully insulate the economy from the deflation trap, the resulting path is cyclical and exhibits overshooting of the inflation target after the economy is pushed out of the deflationary region. There are big fluctuations in inflation, output and government spending in the initial stages of the dynamics, a feature that was not seen in the short-horizon learning examined in Evans, Guse, and Honkapohja (2008). The reason for the large fluctuations is as follows. The combined monetary and fiscal easing during the initial period of pessimistic expectations leads to high levels of government spending and output, which in turn substantially increases $y^{e}$. When the initial period of easing ends at around $\tau=0.1, \pi^{e}$ is near the threshold value $\tilde{\pi}_{1}$, but $y^{e}$ is above the value corresponding to the targeted steady state. For a period of time $g_{t}$ remains at the normal value $\bar{g}$ 
and Figure 2 applies. It can be seen that the economy is in a region northwest of the targeted steady state, implying that $\pi^{e}$ and $y^{e}$ increase. Eventually the economy enters a region northeast of the $\pi^{*}$ steady state, with increasing $\pi^{e}$ and decreasing $y^{e}$. The next phase is in the region southeast of the $\pi^{*}$ steady state, with decreasing $\pi^{e}$ and $y^{e}$. This is followed by a phase in the region southwest of the $\pi^{*}$ steady state, and a second time interval during which aggressive fiscal policy is followed before gradual convergence to the targeted steady state. This particular simulation shows that the cyclical adjustment path to the targeted steady state can entail more than one time interval during which the thresholds for aggressive policy are binding.

These numerical results raise the question of whether alternative versions of our combined policy of monetary and fiscal easing can insulate the economy from deflation traps with smaller fluctuations in output and inflation. In Evans, Guse, and Honkapohja (2008) interest rates responded to current rather than expected inflation, and it is possible this would improve performance under infinite-horizon learning. One related issue to examine is the performance of interest-rate rules that additionally depend on actual or expected output (or net output). Based on the steady-state relationship between output and inflation, these more general Taylor rules are unlikely to change the number of steady states, and hence will not eliminate deflation traps, but they may improve the cyclical performance of the economy. Other possible modifications of policy include fiscal responses that are smoother and that respond countercyclically to high expected output and inflation, and explicit commitments to temporary increases in government spending with a suitable time profile.

The time-path of public debt is an important feature not shown in Figures 5 and 6 . The large increases in government spending in the early periods obviously lead to a substantial increase in public debt. However, because $g_{t}$ eventually converges to $\bar{g}$ and because the tax rule (5) is passive in the sense of Leeper (1991), the debt level eventually returns to the normal steady state value. In the case of Euler equation learning this was illustrated in the numerical simulations of Evans, Guse, and Honkapohja (2008). An implication of the result that the debt level stabilizes in the long run is that the transversality condition holds ex post as well as ex ante.

Noting the critical role of fiscal policy in stabilizing inflation, one might ask whether we could dispense entirely with aggressive monetary policy and simply resort to aggressive fiscal policy whenever $\pi_{t}$ threatens to fall below $\tilde{\pi}_{1}$ ? While the answer is yes, we think our combined policy is clearly 
preferable because there are good reasons to treat monetary policy as the primary tool for counter-cyclical macroeconomic policy. If extensive government spending is used guarantee the inflation threshold, then it is likely that much of the spending will be wasteful in the sense that private consumption would be more highly valued. We therefore prefer to use fiscal policy as a policy of last resort to ensure the inflation threshold.

\section{Conclusions}

When monetary policy is conducted using a standard Taylor rule, the intended steady state is locally stable under learning. However, the economy is not globally stable under learning, and this remains true even if agents make decisions based on infinite-horizon optimization problems. A large exogenous negative shock to expectations can lead to a deflation trap in which expected deflation and low output is reinforced under learning and the economy fails to return to the intended equilibrium. Deflation traps can be avoided by a policy of aggressive monetary and fiscal easing if inflation falls below a suitable threshold, such as zero net inflation. Interestingly, current monetary and fiscal policies to combat the ongoing global economic crisis are qualitatively in line with the aggressive policies discussed in this paper.

The policy of combined monetary and fiscal easing is effective in avoiding deflation even though households are assumed to make consumption decisions using a perceived life-time budget constraint that incorporates Ricardian equivalence. Although our suggested policy successfully insulates the economy against deflation traps, in some cases there are substantial fluctuations in output and inflation along the transition back to the intended steady state. As briefly discussed above, finding simple policies that reduce the fluctuations in output and inflation, during this transition, is a high priority for future research. 


\section{References}

AdAm, K., And R. M. Billi (2007): "Discretionary Monetary Policy and the Zero Lower Bound on Nominal Interest Rates," Journal of Monetary Economics, 54, 728-752.

Benhabib, J., S. Schmitt-Grohe, and M. Uribe (2001): "The Perils of Taylor Rules," Journal of Economic Theory, 96, 40-69.

(2002): "Avoiding Liquidity Traps," Journal of Political Economy, $110,535-563$.

Coenen, G., A. Orphanides, and V. Wieland (2004): "Price Stability and Monetary Policy Effectiveness when Nominal Interest Rates are Bounded at Zero," Advances in Macroeconomics, 4(1), Article 1.

Eggertsson, G. B., and M. Woodford (2003): "The Zero Bound on Interest Rates and Optimal Monetary Policy," Brookings Papers on Economic Activity, (1), 139-233.

Eusepi, S., and B. Preston (2007): "Central Bank Communication and Expectations Stabilization," Working paper nr.13259, NBER.

Evans, G. W., E. Guse, and S. Honkapohja (2008): "Liquidity Traps, Learning and Stagnation," European Economic Review, 52, 1438-1463.

Evans, G. W., And S. Honkapohja (2001): Learning and Expectations in Macroeconomics. Princeton University Press, Princeton, New Jersey.

(2005): "Policy Interaction, Expectations and the Liquidity Trap," Review of Economic Dynamics, 8, 303-323.

- (2009): "Learning and Macroeconomics," Annual Review of Economics, forthcoming, 1 .

Evans, G. W., S. Honkapohja, and K. Mitra (2009): "Anticipated Fiscal Policy and Adaptive Learning," Journal of Monetary Economics, forthcoming.

Evans, G. W., S. Honkapohja, and P. Romer (1998): "Growth Cycles," American Economic Review, 88, 495-515. 
Krugman, P. R. (1998): "It's Baaack: Japan's Slump and the Return of the Liquidity Trap," Brookings Papers on Economic Activity, (2), 137-205.

Leeper, E. M. (1991): 'Equilibria under 'Active' and 'Passive' Monetary and Fiscal Policies," Journal of Monetary Economics, 27, 129-147.

Marcet, A., and T. J. Sargent (1989): "Convergence of Least-Squares Learning Mechanisms in Self-Referential Linear Stochastic Models," Journal of Economic Theory, 48, 337-368.

Preston, B. (2005): "Learning about Monetary Policy Rules when LongHorizon Expectations Matter," International Journal of Central Banking, $1,81-126$.

_ (2006): "Adaptive Learning, Forecast-based Instrument Rules and Monetary Policy," Journal of Monetary Economics, 53, 507-535.

Rotemberg, J. J. (1982): "Sticky Prices in the United States," Journal of Political Economy, 90, 1187-1211.

Sargent, T. J. (2008): "Evolution and Intelligent Design," American Economic Review, 98, 5-37.

Svensson, L. E. (2003): "Escaping from A Liquidity Trap and Deflation: The Foolproof Way and Others," Journal of Economic Perspectives, 17, $145-166$.

Wallace, N. (1981): "A Modigliani-Miller Theorem for Open-Market Operations," American Economic Review, 71, 267-274. 